\title{
Influence of Microalgal Bio-Oil on the Lubrication Properties of Engine Oil
}

\author{
Yufu $\mathrm{Xu}^{1 *}$, Yubin Peng ${ }^{1}$, Xiaojing Zheng ${ }^{2}$, Huabi Wang ${ }^{1}$ and Xianguo $\mathrm{Hu}^{1}$ \\ ${ }^{1}$ Institute of Tribology, School of Mechanical and Automotive Engineering, Hefei University of Technology, Hefei 230009 - China \\ 2 School of Arts and Media, Hefei Normal University, Hefei 230601 - China \\ e-mail: xuyufu@hfut.edu.cn \\ * Corresponding author
}

\begin{abstract}
In order to accelerate and expand the application of bio-energy, two kinds of microalgal bio-oils, prepared via co-liquefaction of Chlorella and Spirulina under sub- and supercritical ethanol conditions, were used as partial substitutes for the engine oil CD SAE 15W-40. The friction and wear behaviors of the oils were tested on a four-ball tribometer, referring to the ASTM D4172 standard conditions. The micro-morphology, profiles, roughness and chemical valences of typical elements on the rubbed surfaces were characterized by Scanning Electron Microscopy (SEM), surface profiler and X-ray Photoelectron Spectroscopy (XPS), respectively. The results showed that both of the bio-oils had good lubrication properties. The suitable weight content of the bio-oils in the engine oil was $10 \%$. The lubrication properties of the Bio-Oil $\left(B O_{\text {sup }}\right)$ prepared in supercritical ethanol were a little better than those of the Bio-Oil $\left(B O_{s u b}\right)$ prepared in subcritical ethanol. The lubricating mechanisms were ascribed to the combined actions of various lubricating films, including boundary lubrication, and deposited films and tribological chemical reaction films. The stronger tribological chemical effects of $B O_{\text {sup }}$ from higher contents of $N$-containing compounds contributed to its better lubrication properties than those of $B O_{\text {sub }}$.
\end{abstract}

Résumé - Influence de bio-huiles issues d'algues sur les propriétés de lubrification d'une huile moteur - Afin d'accélérer et d'étendre l'application des bioénergies, deux types de bio-huiles issues d'algues, préparées par co-liquéfaction de Chlorella et Spirulina dans de l'éthanol à l'état sous- et supercritiques, ont été utilisés comme substituts partiels de l'huile moteur CD SAE 15W-40. Les comportements d'usure et de frottement avec ces huiles ont été testés sur un tribomètre à quatre billes, en se référant aux conditions de la norme ASTM D4172. La micromorphologie, les profils et la rugosité de surface ainsi que les valences chimiques des éléments typiques sur les surfaces frottées ont été respectivement caractérisés par une microscopie à balayage électronique (SEM, Scanning Electron Microscopy), par un profilomètre de surface et par spectroscopie photo-électronique des rayons X (XPS, X-ray Photoelectron Spectroscopy). Les résultats ont montré que les bio-huiles avaient toutes deux de bonnes propriétés de lubrification. La teneur en poids adaptée des bio-huiles dans l'huile moteur était de $10 \%$. Les propriétés de lubrification de la bio-huile $\left(\mathrm{BO}_{\text {sup }}\right)$ préparée dans de l'éthanol supercritique ont été légèrement meilleures que celles de la bio-huile $\left(\mathrm{BO}_{\mathrm{sub}}\right)$ préparée dans de l'éthanol sous-critique. Les mécanismes de lubrification ont été attribués aux actions combinées de différents films de lubrification (y compris un graissage à film d'huile, et de films de dépôts) et de films de réaction chimique tribologiques. Les effets tribo-chimiques plus forts de l'huile $\mathrm{BO}_{\text {sup }}$ contenant des teneurs supérieures en composés contenant de l'azote ont contribué à rendre ses propriétés de lubrification supérieures à celles de l'huile $\mathrm{BO}_{\text {sub }}$. 


\section{INTRODUCTION}

The lubrication properties of automotive fuels are important for vehicles. Active sulfur in the fuels is the main antiwear component; however, recently, owing to the demands for environmental protection, the sulfur content of automotive fuels is restricted to $10 \mathrm{ppm}$, which leads to the malignant wear of some key engine parts including the spray nozzle, injection pump and fuel filter, etc., since these parts are mainly lubricated by the fuels [1]. Therefore, the lubricity of a novel low-sulfur fuel is worth studying.

Bio-oil has been considered as one of the most promising alternative fuels for traditional Diesel oil. However, there are some obvious disadvantages of the bio-oil, including low heating value, high oxygen content, high viscosity and high corrosive properties, which prevent the application of the bio-oil in automotive engines $[2,3]$. Thus, many researchers have focused on upgrading the bio-oil [4-8]. Sub- and supercritical technology is proved an effective way to solve these problems. Actually, because the bio-oil has low sulfur content, the lubrication properties of the bio-oil before and after upgrading are worthy of attention in particular. We previously studied the lubricity of a blend of bio-oil from rice husk and Diesel oil $[9,10]$. The results showed that the lubricity of the fuel blend was better than that of the traditional Diesel fuel. However, the antiwear properties of the fuel blend were inferior to those of conventional Diesel fuel. As known, the raw material and the preparation process have a significant influence on the properties of the bio-oil. Compared with other biomass, microalgae have a higher photosynthetic rate, faster growth rate and higher yield. Bio-oil from microalgae has become a hot topic in biomass energy [11-13]. Unfortunately, to the best of our knowledge, the lubrication properties of microalgal bio-oil have not been reported.

In view of the fact that there are some nitrogen elements in the microalgal bio-oil [14], the cost of removal of N-containing components is high when using the bio-oil as fuel. Moreover, the viscosity of the bio-oil is high and nitrogen is an environmentally friendly antiwear component [15]. Therefore, here we used the bio-oil as a renewable partial substitute for the conventional engine lubricant oil. Two kinds of novel microalgal bio-oils from co-liquefaction of Chlorella and Spirulina were prepared under sub- and supercritical ethanol conditions. The basic components and tribological performances of the bio-oils were characterized, and the lubrication mechanisms are discussed in order to provide a scientific basis for expanding the application of the microalgal bio-oil.

\section{EXPERIMENTAL}

\subsection{Materials}

Two kinds of microalgae, Chlorella and Spirulina, were purchased from Wudi Lv Qi Bioengineering Co. Ltd. Anhydrous ethanol was purchased from Hefei Medicines Pharmaceutical Co. The CD SAE 15W-40 Diesel engine oil was a product of China Petrifaction the Great Wall Lubricating Oil Co. $L t d$. All other reagents were analytically pure.

\subsection{Preparation of the Microalgal Bio-Oils}

The preparation process was carried out in an autoclave and the details and similar experiments are described in our previous work [16]. A typical test is described as follows. The algal powders, $2.8 \mathrm{~g}$ Chlorella and $4.2 \mathrm{~g}$ Spirulina, were mixed with $70 \mathrm{~mL}$ anhydrous ethanol and then placed inside the reactor. The reaction system was sealed and the upper air was replaced with 2.0 MPa nitrogen. The reactor was heated to a set temperature $\left(230^{\circ} \mathrm{C}\right.$ or $\left.250^{\circ} \mathrm{C}\right)$ at a rate of $10^{\circ} \mathrm{C} / \mathrm{min}$, keeping the reactor at the set temperature for $30 \mathrm{~min}$. After that, the reactor was cooled to room temperature and the exhaust valve was opened to release the pressure of the autoclave. The liquid products were separated with filtration, and the solvent was removed by vacuum distillation at $68^{\circ} \mathrm{C}$ and $0.03 \mathrm{MPa}$. The condensed dark brown viscous liquid was then collected as bio-oil. One of the bio-oils $\left(\mathrm{BO}_{\text {sub }}\right)$ was produced under subcritical ethanol conditions at $230^{\circ} \mathrm{C}$ and $\sim 5 \mathrm{MPa}$. The other bio-oil $\left(\mathrm{BO}_{\text {sup }}\right)$ was prepared under supercritical ethanol conditions at $250^{\circ} \mathrm{C}$ and $\sim 9 \mathrm{MPa}$.

\subsection{Characterization of the Bio-Oils}

The basic elements $\mathrm{C}, \mathrm{H}, \mathrm{S}$ and $\mathrm{N}$ were analyzed by a EuroEA3000 model elemental analyzer (Leeman Ltd, USA). The contents of $\mathrm{O}$ were calculated by difference. The chemical structures and component analysis were performed using a Spectrum 100 model Fourier Transform InfraRed spectrometer (FTIR, PerkinElmer, USA) within the range of $4000-450 \mathrm{~cm}^{-1}$.

\subsection{Tribological Tests}

The friction and wear tests were performed on a MQ-800 model four-ball tribometer (Jinan Testing Machine Manufacturing Co. Ltd, China), referring to the ASTM D4172 standard conditions (speed: $1450 \mathrm{rpm}$, load: $392 \pm 4 \mathrm{~N}$, testing time: $30 \mathrm{~min}$, temperature: $25 \pm 2^{\circ} \mathrm{C}$ ). As reported in our previous work [17], the lubricant oils were the conventional Diesel engine oil SAE CD 15W-40 and a blend of bio-oil and $15 \mathrm{~W}-40$. The weight percent of bio-oil in the blend oils was $5 \%, 10 \%$ and $15 \%$, respectively. Each oil sample and test condition was repeated three times to estimate the deviations. The testing balls with $12.7 \mathrm{~mm}$ diameter are made of GCr15 steel (AISI 52100) with a hardness of $60 \pm 1$ $\mathrm{HRC}$ and the roughness $(R a)$ is less than $0.020 \mu \mathrm{m}$. The friction force of the testing process was recorded in real time and automatically converted into the friction coefficient. 


\subsection{Analysis of Wear Surface}

After wear tests, the steel balls were washed in acetone. The Wear Scar Diameters (WSD) of the lower balls and wear scar width of upper balls were measured by a TPF-1 model optical microscope (Olympus Co., Japan). The profiles and roughness of worn surfaces of upper balls were analyzed along the vertical direction of friction by a HT-SURF 10000 model surface roughness measurement system (Harbin Precision Co., China). The magnified surface topographies of worn surfaces of upper balls were observed by a JSM-6490LV SEM (JEOL, Japan). The contents and chemical valences of the typical elements on the rubbed surfaces of upper balls were characterized by an ESCALAB 250 model XPS (Thermo Scientific, USA).

\section{RESULTS AND DISCUSSION}

\subsection{Components of the Bio-Oils}

The elemental contents of the bio-oils are shown in Table 1; it can be seen that the contents of $\mathrm{S}$ of the bio-oils were not detected because they were less than $0.01 \%$. This result was consistent with a previous study [13] and proved their environmentally friendly properties. Besides $\mathrm{C}, \mathrm{H}$ and $\mathrm{O}$ elements, there was $3.59 \%$ and $4.66 \%$ $\mathrm{N}$ in the two kinds of microalgal bio-oils, $\mathrm{BO}_{\text {sub }}$ and $\mathrm{BO}_{\text {sup, }}$, respectively, which came from the algal protein of the microalgae [13].

The detailed chemical structures and components were analyzed from the FTIR results (Fig. 1). As can be seen, the very similar figures show that the two kinds of bio-oils have very similar components. A wide peak at 3200 $3600 \mathrm{~cm}^{-1}$ was ascribed to stretching vibration of $\mathrm{O}-\mathrm{H}$ or $\mathrm{N}-\mathrm{H}$ groups, which indicated the presence of alcohols, water or amide in the bio-oils. The absorption at $2850-2950 \mathrm{~cm}^{-1}$ was the stretching vibration of the $\mathrm{C}-\mathrm{H}$ group of hydrocarbon [18]. The peaks at $1650-1800 \mathrm{~cm}^{-1}$ were the absorption of the $\mathrm{C}=\mathrm{O}$ group of ketone, ester or acid. The peaks at about $1100 \mathrm{~cm}^{-1}$ were the vibration of the $\mathrm{C}-\mathrm{O}$ group of alcohol, ether or ester. The absorption at $1400-1480 \mathrm{~cm}^{-1}$ was ascribed to the formation vibration of the $\mathrm{C}-\mathrm{H}$ group of hydrocarbon in $\mathrm{BO}_{\text {sub; }}$; however, the peak shift to the

TABLE 1

Elemental contents of the bio-oils

\begin{tabular}{c|c|c|c|c}
\hline Oils & $\mathrm{C} / \mathrm{wt} \%$ & $\mathrm{H} / \mathrm{wt} \%$ & $\mathrm{~N} / \mathrm{wt} \%$ & $\mathrm{O} / \mathrm{wt} \%$ \\
\hline $\mathrm{BO}_{\text {sub }}$ & 57.58 & 7.44 & 3.59 & 31.39 \\
\hline $\mathrm{BO}_{\text {sup }}$ & 59.09 & 8.49 & 4.66 & 27.76 \\
\hline
\end{tabular}

${ }^{a}$ by difference.

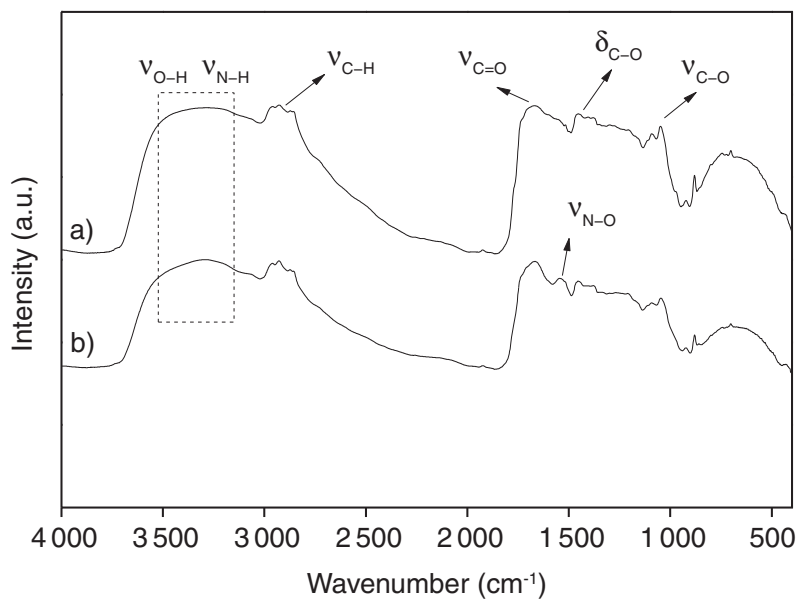

Figure 1

FTIR spectra of: a) $\mathrm{BO}_{\text {sub }}$, b) $\mathrm{BO}_{\text {sup }}$.

$1500-1550 \mathrm{~cm}^{-1}$ belonged to the stretching vibration of the $\mathrm{N}-\mathrm{O}$ group in $\mathrm{BO}_{\text {sup }}$. This indicated that there were more $\mathrm{N}$-containing compounds in $\mathrm{BO}_{\text {sup }}$ than in $\mathrm{BO}_{\text {sub }}$. This was also confirmed by elemental analysis (Tab. 1). From all the above analysis, it can be seen that the components of the microalgal bio-oil were similar to the results reported by other authors [12], who studied many complex compounds including alcohol, ether, ester, acid, ketone, hydrocarbon, $\mathrm{N}$-containing chemicals, etc.

\subsection{Antifriction Properties of the Bio-Oils}

The effect of the content of the bio-oils on the average friction coefficient is shown in Figure 2. The error bars in this figure indicate the deviation of the average friction coefficient in the three duplicate tests. It can be seen that the average friction coefficient decreased significantly with the addition of the bio-oils, which shows the excellent antifriction properties of the bio-oils. However, the decrease rate of the antifriction declined with the increase in the content of the bio-oils. Additionally, the effect of antifriction of $\mathrm{BO}_{\text {sup }}$ was a little better than that of $\mathrm{BO}_{\text {sub. This is mainly }}$ caused by a higher content of the $\mathrm{N}$-containing compounds in $\mathrm{BO}_{\text {sup }}$, since they can form an adsorbed film on the steel rubbing surface [19]. The integrity and strength of the lubrication film improved with the increase in the bio-oils, and thus the average friction coefficient decreased sharply. This decrease became slight when the rubbing surface had a saturated adsorption of the bio-oils, since continual increase in bio-oil had little effect on the integrity and strength of the adsorbed film after saturated adsorption [20]. 


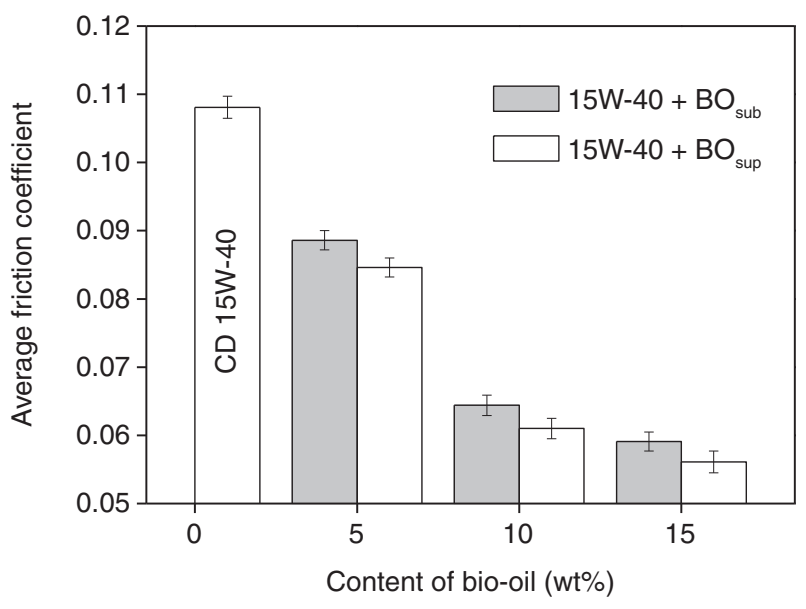

Figure 2

Effect of content of the bio-oils on the average friction coefficient.

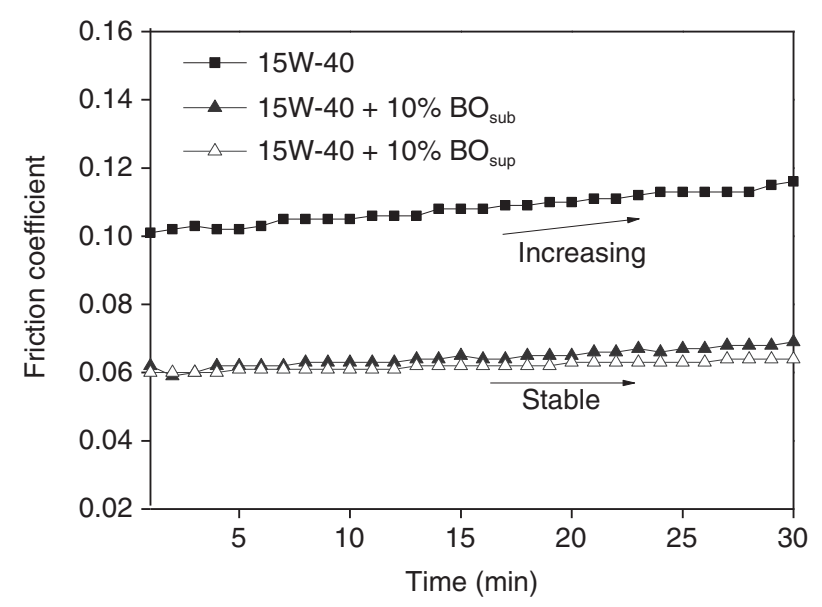

Figure 3

Variation of friction coefficient with time under different oils.

The variations of the real-time friction coefficient of Diesel engine oil and blend oils (with 10\% bio-oil) with time are shown in Figure 3. It can be noted that with the increase in friction time, the friction coefficient of $15 \mathrm{~W}-40$ increased slightly. This phenomenon was also observed by $\mathrm{Hu}$ [21]. The friction coefficient decreased significantly after adding $10 \%$ bio-oil to the conventional engine oil, and the friction coefficient decreased by $40.4 \%$ and $42.7 \%$, when using, respectively, $10 \% \mathrm{BO}_{\text {sub }}$ and $10 \% \mathrm{BO}_{\text {sup }}$ as additives in $15 \mathrm{~W}-40$. Moreover, compared with the pure $15 \mathrm{~W}-40$ without bio-oil, the friction coefficients of the blend oils are more stable. Therefore, the bio-oils can not only decrease the

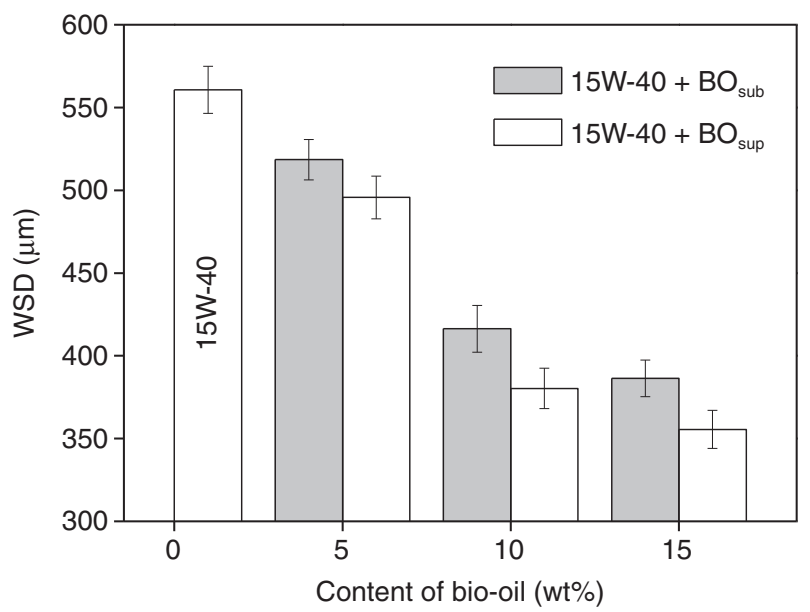

Figure 4

Effect of content of the bio-oils on the average WSD.

friction coefficient, but also contribute to maintaining the stability of lubrication.

The main reason for this was that, compared with the hydrocarbon chains of traditional lubricating oil such as CD SAE 15W-40, the various polar groups of the bio-oils can form stronger secondary bonds including hydrogen bonds on the friction surfaces [22], which play an important boundary lubrication protection role.

\subsection{Antiwear Properties of the Bio-Oils}

The effect of the content of the bio-oils on the average WSD of the lower balls is presented in Figure 4. The error bars in this figure denote the deviation of WSD of the stationary balls in the three duplicate tests. As can be seen from this figure, the WSD decreased with the increase in the content of the bio-oils; however, just like the antifriction properties, the decrease rate of the wear declined with the increase in the content of the bio-oils. Thus, the suitable weight content of the bio-oils in the engine oil was $10 \%$. Additionally, the antiwear effect of $\mathrm{BO}_{\text {sup }}$ was a little better than that of $\mathrm{BO}_{\text {sub }}$. This can be explained by the fact that there are more N-containing compounds in the $\mathrm{BO}_{\text {sup }}$ than in the $\mathrm{BO}_{\text {sub }}$ (Tab. 1), since nitrogen is an excellent antiwear component $[15,23$, 24]. The chemical activities of $\mathrm{N}$ in friction are discussed with the XPS results in the following section.

\subsection{Lubrication Mechanisms of the Bio-Oils}

The optical micrographs of the wear scars on the steel balls lubricated with different oils are given in Figure 5. As shown 

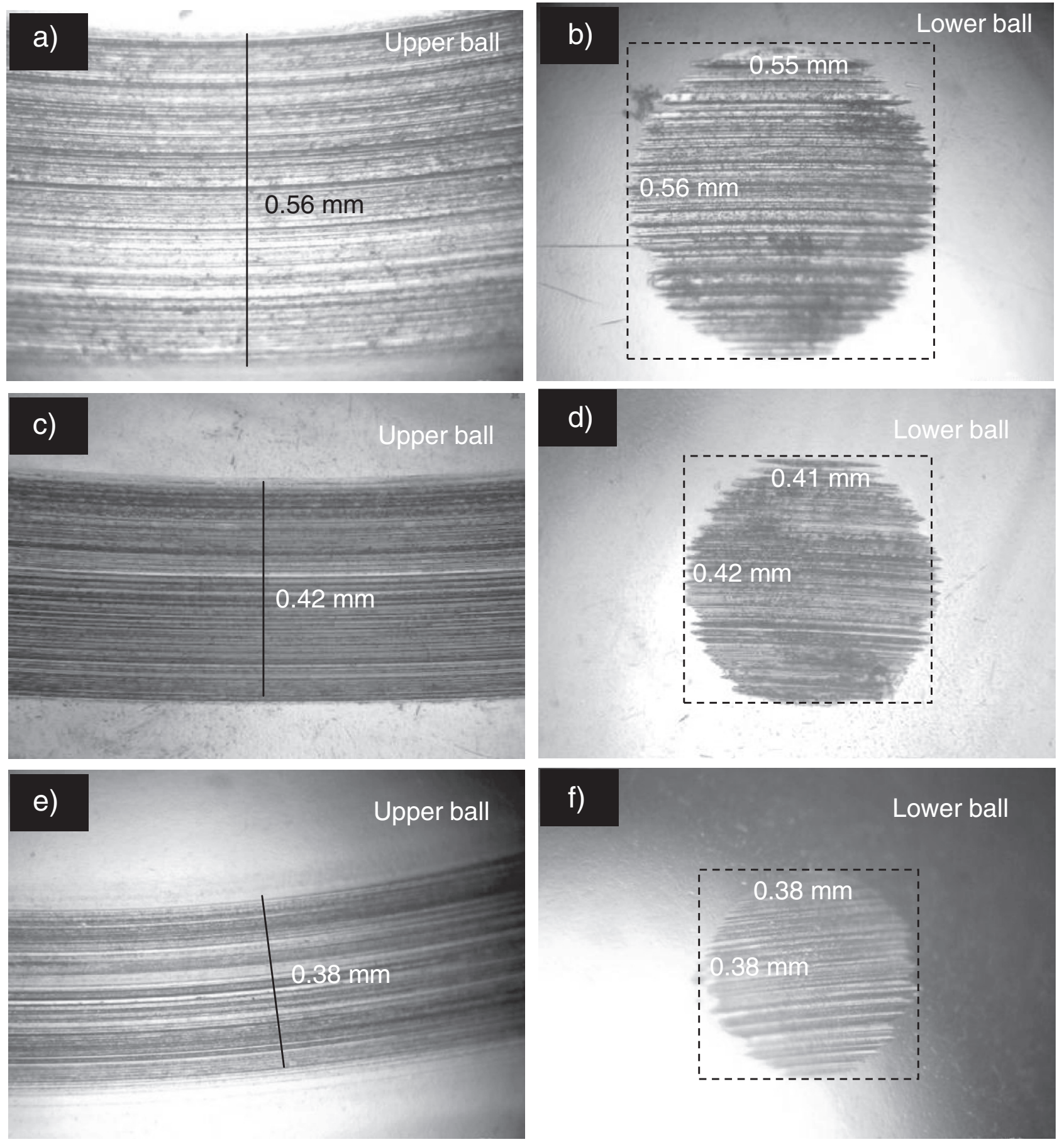

Figure 5

The optical micrographs of the wear scars on the steel balls lubricated with: a, b) $\left.15 \mathrm{~W}-40 ; \mathrm{c}, \mathrm{d}) 15 \mathrm{~W}-40+10 \% \mathrm{BO}_{\text {sub }} ; \mathrm{e}, \mathrm{f}\right) 15 \mathrm{~W}-40+10 \% \mathrm{BO}_{\text {sup }}$.

in this figure, there was a friction band on the upper balls and a round spot on the lower balls. The upper steel ball concerning $15 \mathrm{~W}-40$ presented the largest wear scar width, and both of the wear scars of upper balls and lower balls were decreased after adding the bio-oils to $15 \mathrm{~W}-40$. The widths of the wear scars of upper balls were consistent with those of the lower balls, and this figure also shows that plowing was the main pattern of wear $[25,26]$ on the steel balls. 


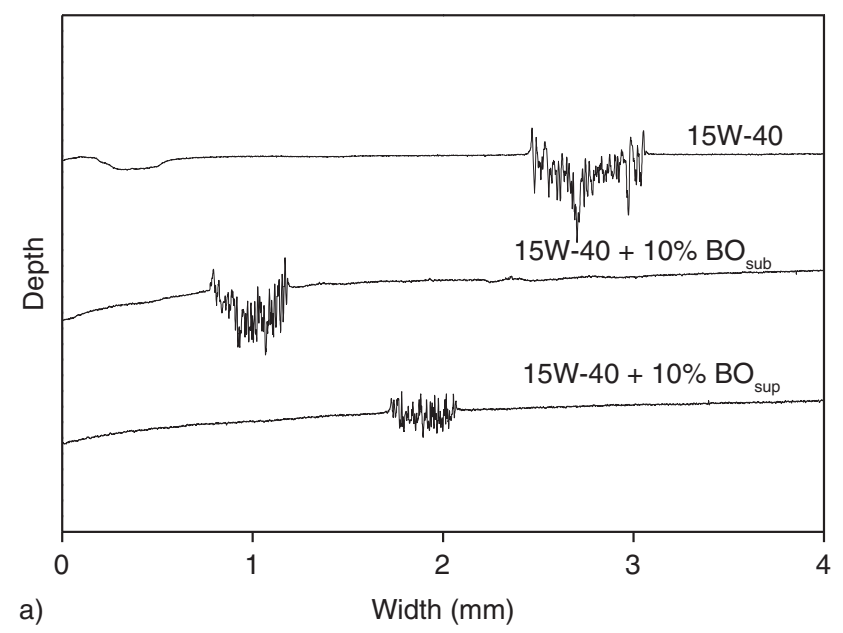

Figure 6

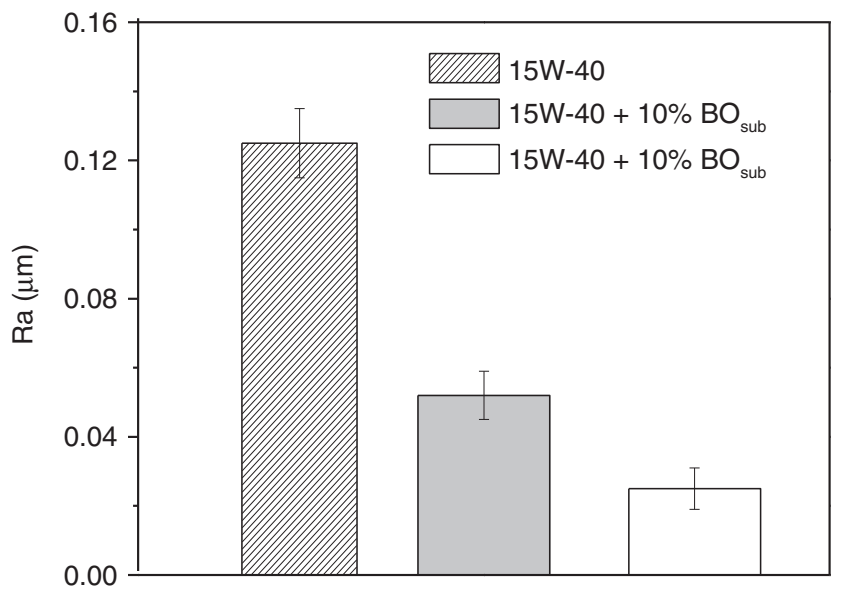

b)

Lubricants

Worn surface profiles a) and surface roughness b) of the wear scars of upper balls lubricated with different oils.

Figure 6 provides the worn surface profiles (Fig. 6a) and surface roughness (Fig. 6b) of the wear scars of upper balls lubricated with different oils. The upper ball lubricated with $15 \mathrm{~W}-40$ with $10 \% \mathrm{BO}_{\text {sup }}$ added presented the smallest wear scar width, depth and surface roughness $(R a)$. The wear scar widths, depths and surface roughness of the upper steel balls lubricated with blend oils (adding $10 \% \mathrm{BO}_{\text {sub }}$ or $\mathrm{BO}_{\text {sup }}$ ) were smaller than those lubricated with $15 \mathrm{~W}-40$. This figure also indicates that the bio-oils helped to protect the friction surface from severe wear. These results were consistent with the tribological behaviors of the lubricants.

In order to know the detailed wear information of the friction surfaces of the steel balls, the SEM images of the wear scars of upper balls lubricated with different oils are shown in Figure 7. The worn surface lubricated with $15 \mathrm{~W}-40$ had many obvious spalling pits, wide furrows and wear humps, and these were typical spalling wear on the contact area [25]. The spalling pits on the worn surface disappeared, and the furrows and humps became smaller when lubricated with $15 \mathrm{~W}-40$ with $10 \% \mathrm{BO}_{\text {sub }}$ added, and furrow wear was the main manner of wear [27]. There were little light furrows and small humps on the worn surface lubricated with $15 \mathrm{~W}-40$ with $10 \% \mathrm{BO}_{\text {sup }}$ added, which can be ascribed to the lubricating action of organic compounds in the bio-oils.

Figure 8 shows the XPS spectra of typical elements on the friction surfaces of the three upper balls lubricated with $15 \mathrm{~W}-40,15 \mathrm{~W}-40$ with $10 \% \mathrm{BO}_{\text {sub }}$, and $15 \mathrm{~W}-40$ with $10 \%$ $\mathrm{BO}_{\text {sup }}$, respectively, at $1450 \mathrm{rpm}$ under $392 \pm 4 \mathrm{~N}$ for $30 \mathrm{~min}$. The peaks at $\sim 724.6 \mathrm{eV}$ and $\sim 710.9 \mathrm{eV}$ (Fig. 8a) were ascribed to the Fe2p1/2 and Fe2p3/2 of -Fe(III)-O-, respectively, the tribological oxidation production of steel [28]. This was also confirmed by the O1s peak at $\sim 529.7 \mathrm{eV}$ (Fig. 8b), which was caused by the O1s of $\mathrm{Fe}_{2} \mathrm{O}_{3}$ and produced by the tribological oxidation of $\mathrm{Fe}$. There were also two peaks at $\sim 719.9 \mathrm{eV}$ and $\sim 707 \mathrm{eV}$ (Fig. 8a) at the surface lubricated with $15 \mathrm{~W}-40$, which belonged to the $\mathrm{Fe} 2 \mathrm{p} 1 / 2$ and $\mathrm{Fe} 2 \mathrm{p} 3 / 2$ of $\mathrm{Fe}(0)$ simpler substances and they might be detected from the spalling pits. This was consistent with the SEM analysis (Fig. 7a). However, these two peaks disappeared at the surface lubricated with $15 \mathrm{~W}-40$ with added bio-oils. This indicated that the oxidation films on the surface lubricated with $15 \mathrm{~W}-40$ were not complete, and they were improved by adding bio-oils to $15 \mathrm{~W}-40$. Moreover, both of the surfaces lubricated with $15 \mathrm{~W}-40$ with $10 \%$ $\mathrm{BO}_{\text {sub }}$ added and that lubricated with $15 \mathrm{~W}-40$ with $10 \% \mathrm{BO}_{\text {sup }}$ added had a small peak at $\sim 709.4 \mathrm{eV}$, which was attributed to the Fe2p of FeN [29]. This was also confirmed by the N1s peak at $\sim 397.3 \mathrm{eV}$ (Fig. 8c), which was caused by N1s of FeN because of the tribological chemical reaction of $\mathrm{N}$-containing compounds in the bio-oils with the $\mathrm{Fe}$ of the steel balls. The peak at $\sim 404.9 \mathrm{eV}$ (Fig. 8c) was attributed to the nitrites in $15 \mathrm{~W}-40$, and it was covered by FeN after adding the bio-oils. Both Figures $8 \mathrm{a}$ and $8 \mathrm{c}$ show that the relative peak areas of $\mathrm{FeN}$ on the surface lubricated with $15 \mathrm{~W}-40$ with $10 \% \mathrm{BO}_{\text {sup }}$ added were larger than that with $10 \% \mathrm{BO}_{\text {sub }}$ lubricant. This suggested the chemical reaction film of the surface lubricated with $15 \mathrm{~W}-40$ with $10 \% \mathrm{BO}_{\text {sup }}$ added was thicker than that of the surface lubricated with $15 \mathrm{~W}-40$ with $10 \% \mathrm{BO}_{\text {sub }}$ added, which might be the main reason for the better lubricity of $\mathrm{BO}_{\text {sup }}$. 



Figure 7

SEM images of the wear scars of upper balls lubricated with: a) $15 \mathrm{~W}-40$, b) $15 \mathrm{~W}-40+10 \% \mathrm{BO}_{\text {sub }}$, c) $15 \mathrm{~W}-40+10 \% \mathrm{BO}_{\text {sup }}$.

Additionally, the peaks at $\sim 531.4 \mathrm{eV}$ (Fig. 8b) were ascribed to the $\mathrm{O} 1 \mathrm{~s}$ of hydroxides and oxygen-containing compounds [30], which may come from the adsorption and tribological deposition of the chemicals in the lubricant oils. This is also proved by the peaks at $\sim 285.3 \mathrm{eV}$ and $\sim 284.9 \mathrm{eV}$ (Fig. 8d), which belonged to the $\mathrm{C} 1 \mathrm{~s}$ of $\mathrm{C}-\mathrm{O}-\mathrm{C}$, (or $\mathrm{C}-\mathrm{O}-\mathrm{H})$ and $\mathrm{C}-\mathrm{C}($ or $\mathrm{C}-\mathrm{H})$, respectively. From the relative peak area of O1s (Fig. 8b), it was found that the peaks at $\sim 529.7 \mathrm{eV}$ were enhanced significantly after adding the bio-oils to $15 \mathrm{~W}-40$, which indicated that the friction oxidation film improved after substituting $10 \%$ of the conventional engine oil with bio-oils. However, the effect of $\mathrm{BO}_{\text {sub }}$ was more obvious than that of $\mathrm{BO}_{\text {sup }}$, because the friction oxidation film could prevent the surface from further severe wear. It seemed that this result conflicted with the lubricity of the two bio-oils. This might be interpreted by the fact that the strength and integrity of the chemical reaction film of $\mathrm{FeN}$ were better than that of $\mathrm{Fe}_{2} \mathrm{O}_{3}$ [31], and the protection role of $\mathrm{FeN}$ was the main lubrication mechanism of the $\mathrm{BO}_{\text {sup }}$, whereas the protection role of the tribo-oxide film $\mathrm{Fe}_{2} \mathrm{O}_{3}$ was the main lubrication mechanism of the $\mathrm{BO}_{\text {sub. }}$.

The relative atomic contents of typical elements on worn surfaces lubricated with different oils are shown in Table 2. As can be noted, the surface lubricated with $15 \mathrm{~W}-40$ had the highest content of $\mathrm{O}$, the second highest content of $\mathrm{C}$ and the lowest content of $\mathrm{N}$. This showed that the lubricating action of $15 \mathrm{~W}-40$ was mainly attributed to the adsorption and tribological deposition of the carbonaceous compounds in the lubricant oils. The finite strength of the deposition film caused acute spalling wear of the surface lubricated with $15 \mathrm{~W}-40$. The surface lubricated with $15 \mathrm{~W}-40$ with $10 \%$ $\mathrm{BO}_{\text {sub }}$ added had the highest content of $\mathrm{Fe}$ and the second highest content of $\mathrm{O}$, which came from the thickest friction oxidation film. This indicated that the friction oxidation film played an important lubricant role and prevented the surface from further severe wear after adding $10 \% \mathrm{BO}_{\text {sub }}$ to $15 \mathrm{~W}-40$. The content of $\mathrm{Fe}$ on the surface lubricated with $15 \mathrm{~W}-40$ was higher than that on the surface lubricated with $15 \mathrm{~W}-40$ with $10 \% \mathrm{BO}_{\text {sup }}$ added, and one reason might be that iron came from both of the $\mathrm{Fe}_{2} \mathrm{O}_{3}$ and $\mathrm{Fe}(0)$ simpler substances in the spalling pits. The surface lubricated with $15 \mathrm{~W}-40$ with $10 \% \mathrm{BO}_{\text {sup }}$ added had the highest content of $\mathrm{N}$, which came from the tribological reaction production of $\mathrm{FeN}$. The excellent integrity and strength of the FeN film helped to maintain the good lubricating role of $15 \mathrm{~W}-40$ with $10 \% \mathrm{BO}_{\text {sup }}$ added.

According to the above analysis, the lubrication mechanisms of the microalgal bio-oils were ascribed to the combined actions of multiple protective films. On one hand, the adsorption and deposited films composed of carbonaceous compounds (alcohol, ether, ester, acid, ketone, hydrocarbon, etc.) and O-containing polar groups in the bio-oils formed boundary lubrication [32]. On the other hand, the tribo-oxide film composed of $\mathrm{Fe}_{2} \mathrm{O}_{3}$ and frictional chemical reaction film containing $\mathrm{FeN}$ enhanced the integrity and strength of the lubrication films on the friction surface. 

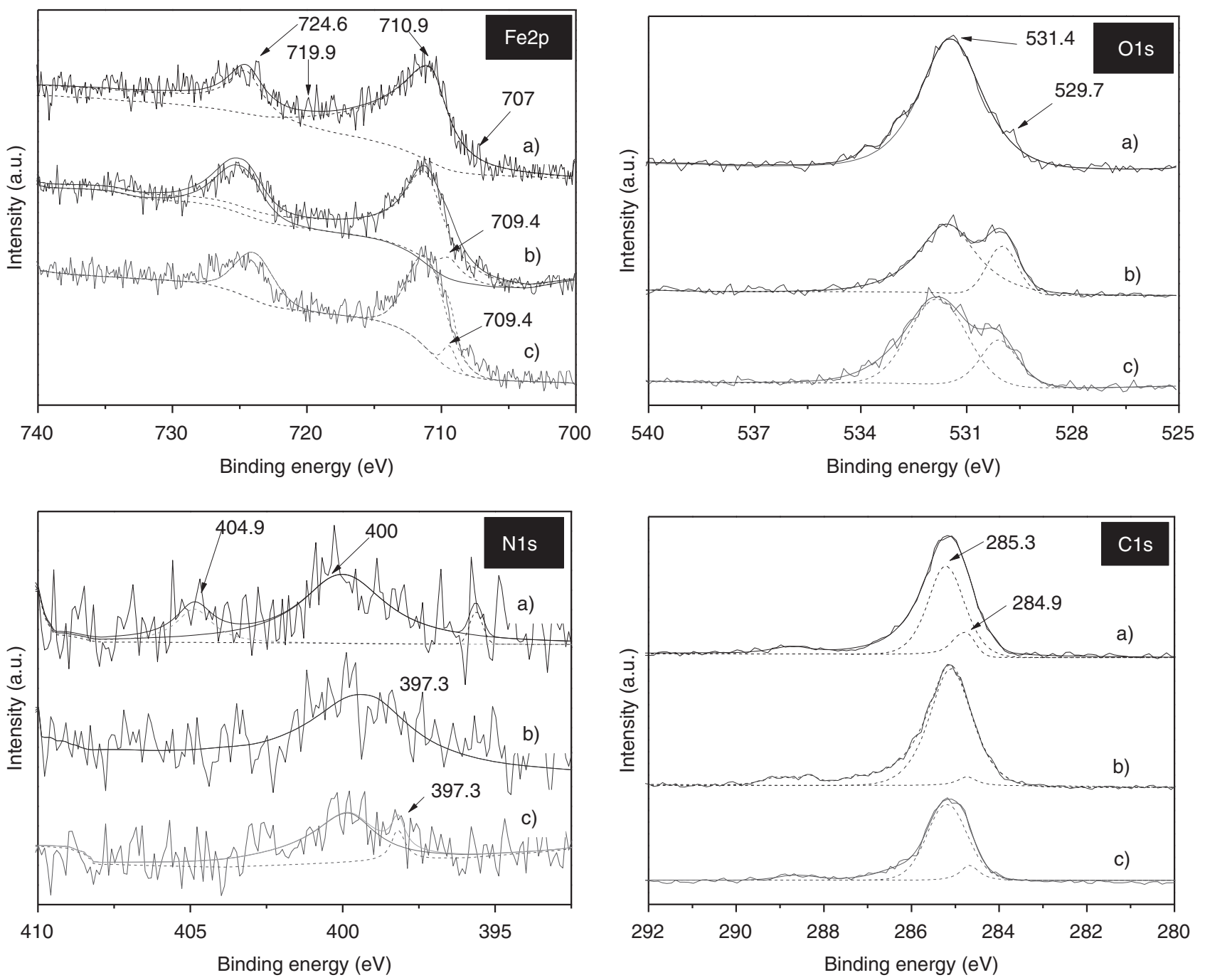

Figure 8

XPS spectra of typical elements on the friction surfaces lubricated with: a) $15 \mathrm{~W}-40$, b) $15 \mathrm{~W}-40+10 \% \mathrm{BO}_{\text {sub }}$, c) $15 \mathrm{~W}-40+10 \% \mathrm{BO}$ sup.

TABLE 2

Relative atomic content of typical elements on worn surfaces lubricated with different oils

\begin{tabular}{c|c|c|c|c}
\hline \multirow{2}{*}{ Worn surfaces } & \multicolumn{4}{|c}{ Atom content (at.\%) } \\
\cline { 2 - 5 } & $\mathrm{Fe}$ & $\mathrm{O}$ & $\mathrm{C}$ & $\mathrm{N}$ \\
\hline Lubricated with 15W-40 & 6.6 & 31.5 & 59.9 & 2 \\
\hline Lubricated with 15W-40+10\% BO sub & 12.2 & 31.3 & 53.3 & 3.2 \\
\hline Lubricated with 15W-40+10\% BO & 4.8 & 29.4 & 62.1 & 3.7 \\
\hline
\end{tabular}

$\mathrm{BO}_{\text {sub }}$ contributed to the integrity of the tribo-oxide film, while $\mathrm{BO}_{\text {sup }}$ helped to form a frictional chemical reaction film composed of FeN. The joint actions of these lubrication films resulted in the excellent antifriction and antiwear behaviors of the bio-oils.

\section{CONCLUSIONS}

The lubrication properties of the bio-oils (prepared via coliquefaction of Chlorella and Spirulina under sub- and supercritical ethanol conditions) as a partial substitute for conventional engine oil SAE CD 15W-40 were studied using a four-ball tribometer. The influence of the contents of the bio-oils and their tribological behaviors were studied. The tribological mechanisms were discussed based on the 
comprehensive analysis of the worn surfaces. The following conclusions can be drawn from this study:

- both of the two kinds of microalgal bio-oils, $\mathrm{BO}_{\text {sub }}$ and $\mathrm{BO}_{\text {sup }}$, had good lubrication properties. The average friction coefficient and wear loss of the steel balls decreased with the increase in the percent of the bio-oils in the engine oil. The frictional stability was enhanced by the introduction of bio-oils;

- the decrease rate of the antifriction and antiwear declined with the increase in the content of the bio-oils, and the optimized weight content of the bio-oils in $15 \mathrm{~W}-40$ was $10 \%$. The lubrication properties of $\mathrm{BO}_{\text {sup }}$ were better than those of $\mathrm{BO}_{\text {sub }}$;

- the lubrication mechanisms were ascribed to the combined actions of multiple lubrication films including boundary lubrication, and deposited films and tribological chemical reaction films from $15 \mathrm{~W}-40$ as the base oil and the bio-oils as additives. The stronger tribological chemical effects of $\mathrm{BO}_{\text {sup }}$ came from its higher contents of $\mathrm{N}$-containing compounds, in accordance with its better lubrication properties.

\section{ACKNOWLEDGMENTS}

The authors wish to express their thanks to Mr. Lulu Yao, Shanbin Yin, Jie Huang and Tanming Lei for their assistance with the present work. The financial support from the National Natural Science Foundation of China (Grant No. 51405124), China Postdoctoral Science Foundation (Grant No. 2014M560505), Anhui Provincial Natural Science Foundation (Grant No. 1408085ME82) and College Students Innovation Experimental Plan Fund of HFUT is gratefully acknowledged.

\section{REFERENCES}

1 Arkoudeas P., Zannikos F., Lois E. (2008) The Tribological Behavior of Essential Oils in Low Sulphur Automotive Diesel, Fuel 87, 17-18, 3648-3654.

2 Baldwin R.M., Feik C.J. (2013) Bio-Oil Stabilization and Upgrading by Hot Gas Filtration, Energy Fuels 27, 6, 3224-3238.

3 Xu Y.F., Yu H.Q., Wei X.Y., Cui Z., Hu X.G., Xue T., Zhang D.Y. (2013) Friction and Wear Behaviors of a Cylinder LinerPiston Ring with Emulsified Bio-Oil as Fuel, Tribology Transactions 56, 3, 359-365.

4 Elkasabi Y., Mullen C.A., Pighinelli A.L.M.T., Boateng A.A. (2014) Hydrodeoxygenation of Fast-Pyrolysis Bio-Oils from Various Feedstocks Using Carbon-Supported Catalysts, Fuel Processing Technology 123, 11-18.

5 Wang C.P., Hu Y.F., Chen Q., Lv C.Y., Jia S.G. (2013) Bio-oil Upgrading by Reactive Distillation Using P-Toluene Sulfonic Acid Catalyst Loaded on Biomass Activated Carbon, Biomass Bioenergy 56, 405-411.
6 Gunawan R., Li X., Lievens C., Gholizadeh M., Chaiwat W., $\mathrm{Hu}$ X., Mourant D., Bromly J., Li C.Z. (2013) Upgrading of Bio-Oil into Advanced Biofuels and Chemicals. Part I. Transformation of GC-detectable Light Species During the Hydrotreatment of Bio-oil Using Pd/C Catalyst, Fuel 111, 709-717.

7 Duan P.G., Xu Y.P., Bai X.J. (2013) Upgrading of Crude Duckweed Bio-Oil in Subcritical Water, Energy Fuels 27, 8, 4729-4738.

8 Xu Y., Zheng X., Yu H., Hu X. (2014) Hydrothermal Liquefaction of Chlorella pyrenoidosa for Bio-Oil Production over Ce/HZSM-5, Bioresource Technology 156, 1-5.

9 Xu Y., Wang Q., Hu X., Li C., Zhu X. (2010) Characterization of the Lubricity of Bio-Oil/Diesel Fuel Blends by High Frequency Reciprocating Test Rig, Energy 35, 1, 283-287.

10 Xu Y.F., Zheng X.J., Yin Y.G., Huang J., Hu X.G. (2014) Comparison and Analysis of the Influence of Test Conditions on the Tribological Properties of Emulsified Bio-Oil, Tribology Letters 55, 3, 543-552.

11 Jena U., Das K.C. (2011) Comparative Evaluation of Thermochemical Liquefaction and Pyrolysis for Bio-oil Production from Microalgae, Energy Fuels 25, 11, 5472-5482.

12 Hu Z.Q., Zheng Y., Yan F., Xiao B., Liu S.M. (2013) Bio-Oil Production through Pyrolysis of Blue-Green Algae Blooms (Bgab): Product Distribution and Bio-Oil Characterization, Energy 52, 119-125.

13 Wang K.G., Brown R.C., Homsy S., Martinez L., Sidhu S.S. (2013) Fast Pyrolysis of Microalgae Remnants in a Fluidized Bed Reactor for Bio-Oil and Biochar Production, Bioresource Technology 127, 494-499.

14 Jena U., Das K.C., Kastner J.R. (2011) Effect of Operating Conditions of Thermochemical Liquefaction on Biocrude Production from Spirulina Platensis, Bioresource Technology 102, 10, 6221-6229.

15 Shum P.W., Xu Y.F., Zhou Z.F., Cheng W.L., Li K.Y. (2012) Study of TiAlSiN Coatings Post-treated with N and C+N Ion Implantations. Part 2: The Tribological Analysis, Wear 274-275, 274-280.

16 Xu Y., Yu H., Hu X., Wei X., Cui Z. (2014) Bio-Oil Production from Algae via Thermochemical Catalytic Liquefaction, Energy Sources, Part A 36, 1, 1-8.

17 Xu Y., Hu X., Yu H., Hu L. (2014) Study of Lubrication Performance and Mechanism of Bio-oils Made from Typical Microalgae, Tribology 34, 3, 291-296 (in Chinese).

18 Bera A., Kumar T., Ojha K., Mandal A. (2013) Adsorption of Surfactants on Sand Surface in Enhanced Oil Recovery: Isotherms, Kinetics and Thermodynamic Studies, Applied Surface Science 284, 87-99.

19 Huang W., Du C., Li Z., Liu M., Liu W. (2006) Tribological Characteristics of Magnesium Alloy Using N-Containing Compounds as Lubricating Additives During Sliding, Wear 260, 1-2, 140-148.

20 Grahn M., Naveira-Suarez A., Pasaribu R. (2011) Effect of ZDDP on Friction in Fretting Contacts, Wear 273, 1, 70-74.

21 Hu E., Hu X., Liu T., Song R., Dearn K.D., Xu H. (2013) Effect of $\mathrm{TiF}_{3}$ Catalyst on the Tribological Properties of Carbon Black-Contaminated Engine Oils, Wear 305, 1-2, 166-176.

22 Kasai P., Raman V. (2006) Hydrogen Bonding in Lubricants for Hard Disk Drives, Tribology Letters 21, 3, 205-216.

23 Xu Y., Zheng X., Hu X., Dearn K.D., Xu H. (2014) Effect of Catalytic Esterification on the Friction and Wear Performance of Bio-Oil, Wear 311, 1-2, 93-100. 
24 Xu Y., Hu X., Yuan K., Zhu G., Wang W. (2014) Friction and Wear Behaviors of Catalytic Methylesterified Bio-oil, Tribology International 71, 168-174.

25 Grün F., Sailer W., Gódor I. (2012) Visualization of the Processes Taking Place in the Contact Zone with in-situ Tribometry, Tribology International 48, 44-53.

26 Xu Y., Zheng X., Hu X., Yin Y., Lei T. (2014) Preparation of the Electroless $\mathrm{Ni}-\mathrm{P}$ and $\mathrm{Ni}-\mathrm{Cu}-\mathrm{P}$ Coatings on Engine Cylinder and Their Tribological Behaviors Under Bio-Oil Lubricated Conditions, Surface and Coatings Technology 258, 790-796.

27 Hu K., Hu X., Wang J., Xu Y., Han C. (2012) Tribological Properties of $\mathrm{MoS}_{2}$ with Different Morphologies in HighDensity Polyethylene, Tribology Letters 47, 1, 79-90.

$28 \mathrm{Hu} \mathrm{K.,} \mathrm{Hu} \mathrm{X.,} \mathrm{Xu} \mathrm{Y.,} \mathrm{Huang} \mathrm{F.,} \mathrm{Liu} \mathrm{J.} \mathrm{(2010)} \mathrm{The} \mathrm{Effect} \mathrm{of}$ Morphology on the Tribological Properties of $\mathrm{MoS}_{2}$ in Liquid Paraffin, Tribology Letters 40, 1, 155-165.
29 Kim W., Kang H.J., Noh S.K., Song J., Kim C.S. (2007) Magnetic and Structural Properties of Fe Ion-Implanted GaN, J. Magnetism Magnetic Materials 316, 2, e199-e202.

30 Schindler M., Hawthorne F.C., Freund M.S., Burns P.C. (2009) XPS Spectra of Uranyl Minerals and Synthetic Uranyl Compounds. II: the O1s Spectrum, Geochimica Cosmochimica Acta 73, 9, 2488-2509.

31 Schilling T., Bron M. (2008) Oxygen Reduction at Fe-NModified Multi-Walled Carbon Nanotubes in Acidic Electrolyte, Electrochimica Acta 53, 16, 5379-5385.

32 Alves S.M., Barros B.S., Trajano M.F., Ribeiro K.S.B., Moura E. (2013) Tribological Behavior of Vegetable Oil-Based Lubricants with Nanoparticles of Oxides in Boundary Lubrication Conditions, Tribology International 65, 28-36.

Manuscript accepted in November 2014 Published online in January 2015 